\title{
Association of ADAM33 gene polymorphisms with asthma in Indian children
}

\author{
Shally Awasthi ${ }^{1}$, Priya Tripathi ${ }^{1}$, Subramaniam Ganesh ${ }^{2}$ and Nuzhat Husain ${ }^{3}$
}

Asthma is the most common chronic disorder in childhood, and asthma exacerbation is an important cause of childhood morbidity and hospitalization. In the present study, the relationship between single-nucleotide polymorphisms (SNPs) of the ADAM33 gene and asthma in Indian children has been examined using a case-control study. Five SNPs of the ADAM33 gene, F+1(rs511898) G/A, S2 (rs528557) G/C, ST+4 (rs44707) A/C, ST+5 (rs597980) C/T and V4 (rs2787094) C/G, were analyzed in 211 asthma cases and 137 controls aged 1-15 years using the PCR-restriction fragment length polymorphism method. Data were statistically analyzed using the $\chi^{2}$-test and logistic regression model. Haplotype estimation and linkage disequilibrium were conducted using the expectation-maximization algorithm. The genotypes and allele frequencies of SNPs S2 and ST+5 of the ADAM33 gene were significantly associated with asthma risk $(P=0.020-<0.001)$, whereas $\mathrm{F}+1, \mathrm{ST}+4$, V4 homozygous mutant genotypes and mutant alleles were significantly associated with increased asthma risk $(P=0.031-<0.001)$. A positive association was also found with haplotypes AGCCT, GGACT and AGCCC $(P=<0.001$, odds ratio $(0 R)=6.10-6.50)$, whereas ACAGT, AGCGC, AGCGT, GCAGC and GCCGT showed protective association with asthma $(P=0.019-0.000,0 R=0.50-0.20)$. Taken together, out results suggest that $A D A M 33$ gene polymorphisms may modify individual susceptibility to develop childhood asthma in the Indian population.

Journal of Human Genetics (2011) 56, 188-195; doi:10.1038/jhg.2010.157; published online 23 December 2010

Keywords: childhood asthma; haplotypes; single-nucleotide polymorphisms (SNPs)

\section{INTRODUCTION}

Complex genetic diseases are highly prevalent in the general population and have a very significant socioeconomic impact on the healthcare system. Asthma is the most common chronic childhood disease in developed nations. ${ }^{1}$ In India, the prevalence of asthma in adults is $2.38 \%^{2}$ and in children it varies from 6 to $31 \% .^{3,4}$ Overall, it affects nearly 155 million people worldwide. ${ }^{5}$ Asthma is defined as a chronic inflammatory disorder of the airways, in which many cells and cellular elements have a role. The symptoms, resulting from airway hyperresponsiveness, include recurrent episodes of wheezing, breathlessness, chest tightness and coughing-especially at night or in the early morning. ${ }^{6}$ These symptoms are often associated with airflow obstruction within the lungs and are reversible-either spontaneously or by therapy. ${ }^{6}$

ADAM33 was first identified as a susceptibility gene for asthma by positional cloning in the year 2002. ${ }^{7}$ ADAM33 is located on chromosome 20p13, and its expression is restricted largely to mesenchymal cells, including fibroblasts and smooth muscle cells. The ADAM family of proteins, characterized by the presence of a disintegrin and metalloprotease domain (ADAM), have a role in cell-cell and cell-matrix interactions, ${ }^{8}$ as well as in cell migration, ${ }^{9,10}$ cell-cell adhesion $^{11}$ and signal transduction. ${ }^{12}$ The ADAMs protein family constitutes a variety of cell surface proteins, including growth factors, cytokines and receptors. ${ }^{8}$ ADAM33 is predicted to have protease activity and a domain structure composed of a signal sequence, prodomain, metalloprotease domain (with a zinc-binding motif), disintegrin domain, cysteine-rich domain (with an EGF-like motif), a transmembrane domain and a cytoplasmic domain. ${ }^{13}$ A number of reports have appeared since the first study documenting the positive association of ADAM33 polymorphism with asthma in the Caucasian population. Associations between distinct single-nucleotide polymorphisms (SNPs) of ADAM33 and various subphenotypes of asthma as well as bronchial hyperresponsiveness have been reported.,14,19-34 Several SNPs in ADAM33 have been shown to be significantly associated with asthma, suggesting an important role for ADAM33 in the etiology of asthma. ${ }^{7,14,19,20,32}$ However, most data available for ADAM33 and asthma have been obtained from Caucasians, but little data on ADAM33 SNPs associated with asthma and atopic disease are available for Asian populations. ${ }^{14,19,21,26,33,34}$ In light of this, we attempted to examine the association of $A D A M 33$ gene polymorphisms $\mathrm{F}+1 \mathrm{G} / \mathrm{A}, \mathrm{S} 2 \mathrm{G} / \mathrm{C}, \mathrm{ST}+4 \mathrm{~A} / \mathrm{C}, \mathrm{ST}+5 \mathrm{C} / \mathrm{T}$ and V4 C/G with asthma in Indian children.

${ }^{1}$ Department of Pediatrics, Chhatrapati Shahuji Maharaj Medical University, Lucknow, India; ${ }^{2}$ Department of Biological Sciences and Bioengineering, Indian Institute of Technology, Kanpur, India and ${ }^{3}$ Department of Pathology, Chhatrapati Shahuji Maharaj Medical University, Lucknow, India

Correspondence: Dr S Awasthi, Department of Pediatrics, Institute of Clinical Epidemiology, Chhatrapati Shahuji Maharaj Medical University, Shahmina Road, Chowk, Lucknow, Uttar Pradesh 226 003, India.

E-mail: shallya@rediffmail.com

Received 1 August 2010; revised 12 October 2010; accepted 15 November 2010; published online 23 December 2010 


\section{MATERIALS AND METHODS}

\section{Subjects}

The study group consisted of 211 cases and 137 controls. They were recruited between August 2007 and September 2009 from the Department of Pediatrics, Chattrapati Shahuji Maharaj Medical University, Lucknow, Uttar Pradesh, India. This study was approved by the institutional ethics committee and written informed consent for participation was obtained from parents/guardians of all the patients. On screening, the patient was suspected to have asthma if one or both of the following criteria were positive: (a) current diagnosis of asthma by the treating pediatrician and (b) the patient was prescribed antiasthma medication in the past. The diagnosis of suspected asthma and the severity of an asthma attack were then confirmed according to the Global Initiative for Asthma criteria (GINA) guidelines. ${ }^{6}$ Asthmatic patients were grouped into the following categories: (i) intermittent, (ii) mild persistent, (ii) moderate persistent and (iii) severe persistent. We excluded patients who had a history of other atopy-related diseases such as allergic rhinitis and diagnosed pulmonary disease tuberculosis. The inclusion criteria for controls were as follows: (1) no symptoms or history of asthma or other pulmonary diseases; (2) no symptoms or history of atopy; and (3) absence of first-degree relatives with a history of asthma or atopy.

\section{Methods}

DNA extraction and genotyping. Genomic DNA was extracted from $3 \mathrm{ml}$ of frozen whole blood using a DNA Extraction Kit (FlixiGene DNA Kit, QIAGEN
GmbH, Hilden, Germany) according to the manufacturer's protocol and following the manufacturer's instructions. We selected five SNPs in the ADAM33 gene (Figure 1), which were shown previously to have an allelic and/or haplotype association with asthma, including F+1(rs511898), V4(rs2787094), ST+4(rs44707), S2 (rs528557) and ST+5(rs597980). Using the unique rs accession numbers, SNP details and sequence data are available through NCBI databases http://www.ncbi.nlm.nih.gov. Genotyping was carried out by polymerase chain reaction restriction fragment length polymorphisms (PCR-RFLP) (Supplementary figure 1). Using isolated genomic DNA as template, PCRs were carried out. Each PCR was performed in a total reaction volume of $15 \mu \mathrm{l}$, with $20 \mathrm{pmol}$ of each primer sequence. PCR products were digested at $37^{\circ} \mathrm{C}$ overnight with $1 \mathrm{U}$ of restriction enzymes. Detailed information on PCR conditions, primer sequences, restriction enzymes and so on is summarized in Table 1 . Nearly $10 \%$ of the samples were randomly selected and genotyped once again to rule out any inconsistency.

\section{Statistical analysis}

EpiINfo6 (available from the centers for Disease control and Prevention (Atlanta, GA, USA; http://www.cdc.gov/epo/epi/epiinfo.htm)) and SPSS 11.5 (Chicago, IL, USA) were used for statistical analysis. The $\chi^{2}$-test was used to determine differences in genotype/allele frequencies and deviation from HardyWeinberg equilibrium. Logistic regression was used to calculate odds ratio (OR). Homozygous genotype for the normal allele of each SNP in the control group was used as reference in calculating OR and $95 \%$ confidence intervals. ${ }^{16}$

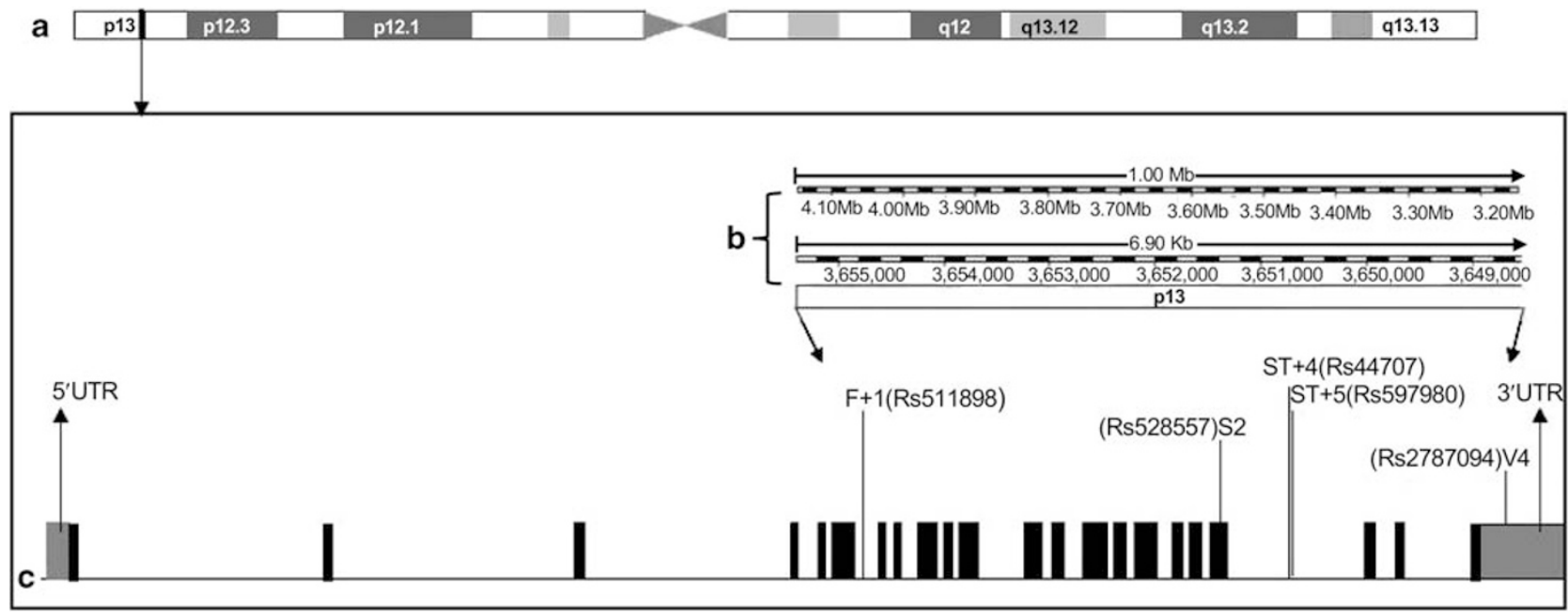

Figure 1 Schematic representation of the ADAM33 gene on chromosome 20. (a) Chromosome 20 showing ADAM33 gene position 20p13. (b) Region covered by five genotyped polymorphisms (SNPs) in Mbs (megabases) and Kbs (kilobases). (c) Position of the genotyped polymorphisms (SNPs) in the $A D A M 33$ gene with respect to the 22 exons (black) and untranslated regions (gray) of the gene.

Table 1 Description of the investigated ADAM33 SNPs

\begin{tabular}{|c|c|c|c|c|c|c|}
\hline rs Number & SNP name & Location & Alleles & $F$ and $R$ primers for $P C R$ & $\begin{array}{l}\text { Annealing temperature }{ }^{\circ} \text { Clextension time } \\
\text { in sec /number of cycles }\end{array}$ & $\begin{array}{l}\text { Digest }(b p) / \\
\text { enzyme }\end{array}$ \\
\hline rs511898 & $\mathrm{F}+1$ & Intron 6 & $G>A$ & $\begin{array}{l}\text { (F) 5'-GTATCTATAGCCCTCCAAATCAGAAGAGCC-3'; } \\
\text { (R) 5'-GGACCCTGAGTGGAAGCTG-3' }\end{array}$ & $60 / 30 / 40$ & $\begin{array}{l}166(\mathrm{~A}) \mathrm{Mspl} \\
29+137(\mathrm{G})\end{array}$ \\
\hline rs2787094 & V4 & 3'UTR & $C>G$ & $\begin{array}{l}\text { (F) 5'-CTCAGGAACCACCTAGGGGAGAAG-3'; } \\
\text { (R) 5'-CAAAGGTCACACAGCCCCTGACCT-3' }\end{array}$ & $60 / 30 / 40$ & $\begin{array}{l}290(C) \text { Pstl } \\
196+94(G)\end{array}$ \\
\hline rs44707 & $\mathrm{ST}+4$ & Intron 19 & $A>C$ & $\begin{array}{l}\text { (F) 5'-CACTTCCTCTGCACAAATCACCTCTGTCGTC-3'; } \\
\text { (R) 5'-GAGCACTCCCAAGACCAGGCTATGTCAG-3' }\end{array}$ & $64 / 30 / 40$ & $\begin{array}{l}277 \text { (C) Hpy166II } \\
246+31(A)\end{array}$ \\
\hline rs528557 & S2 & Exon 19 & $G>C$ & $\begin{array}{l}\text { (F) 5'-AGAGCTCTGAGGAGGGGAACCG-3'; } \\
\text { (R) 5'-GCAGACCATGACACCTTCCTGCTG-3' }\end{array}$ & $64 / 30 / 40$ & $\begin{array}{l}211(\mathrm{C}) \mathrm{Narl} \\
147+64(\mathrm{G})\end{array}$ \\
\hline rs597980 & $\mathrm{ST}+5$ & Intron 19 & $C>T$ & $\begin{array}{l}\text { (F) 5'-TCCCTGGCTCAGATTGCAGTCC-3'; } \\
\text { (R) 5'-ACCACCCAGGTCACAGAGAACTGG-3' }\end{array}$ & $65 / 30 / 40$ & $\begin{array}{l}239(\mathrm{~T}) \text { Acil } \\
177+62(\mathrm{C})\end{array}$ \\
\hline
\end{tabular}

Abbreviations: bp, basepair; F, forward; R, reverse; SNP, single-nucleotide polymorphism. 
Table 2 Distribution of selected characteristics of children

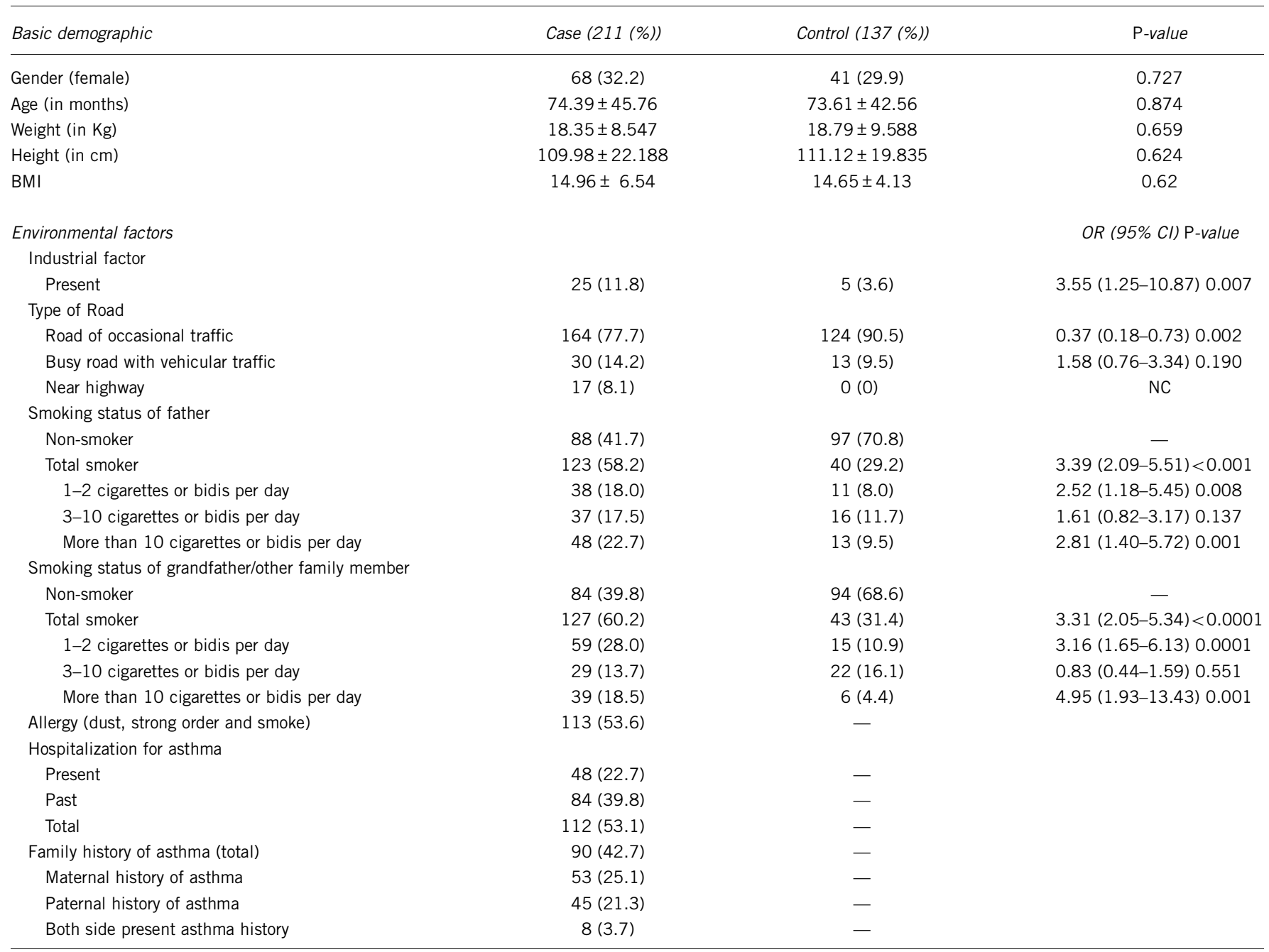

Abbreviations: $\mathrm{BMI}$, body mass index; $\mathrm{Cl}$, confidence interval; $\mathrm{NC}$, not calculated; OR, odds ratio.

Continuous variables were expressed as mean \pm s.d. The significance level for all statistical tests was set at $P<0.05$. $P$-values were corrected ( $P$ corr) for multiple corrections (Bonferroni's correction) in case of further subgrouping or stratification. The $0.05 / \mathrm{N}$ threshold was set up according to the Bonferroni's correction to account for multiple testing issues. $N$ is the number of tested markers (genotypes) for each gene polymorphism. Therefore, for applying Bonferroni's correction, we have multiplied the $P$-value by the number of comparisons (for example, in case of a polymorphism having three genotypes, we multiplied the $P$-value by 3 and for carrier analysis the $P$-value was multiplied by 2). Case-control analysis was carried out to detect possible gene-environment interaction. Fisher's exact test was carried out to avoid type 1 error in the subgroup analyses due to the smaller sample size. ${ }^{16}$ Statistical analyses for the haplotype estimation and linkage disequilibrium (LD) were carried out using the expectation-maximization algorithm (Arlequin software version 2.00). ${ }^{15}$ The SNPAnalyzer (version 1.0; ISTECH; Istech, Kyungkido, Republic of Korea) was used to calculate $D^{\prime}$ value, the measure index of LD. ${ }^{16}$

\section{RESULTS}

This study was conducted from August 2007 to September 2009. Included were 211 cases of asthma, of which 51 (24.2\%) were intermittent, 127 (60.2\%) were mild persistent and 33 (15.6\%) were moderate persistent. No cases of severe persistent asthma were detected.
A total of 137 controls were included in the study. Table 2 shows the selected characteristics of the study population. Compared with controls, cases were likely to have father and grandfather or other family members with a present smoking habit. Proximity to an industrial area and road near a highway were the factors likely to cause a risk of developing disease asthma $(P$-value $<0.05)$. Details regarding environmental risk factors for cases and controls were recorded and analysis was performed for further possible geneenvironment interactions.

\section{Association of ADAM33 gene polymorphisms with asthma} compared with controls, cases with positive family history and total hospitalization

The genotype and allele frequencies of the ADAM33 gene polymorphisms in patients and healthy controls are shown in Table 3 . All five SNPs genotyped were in Hardy-Weinberg equilibrium $(P>0.05)$ in both cases and controls. After comparing genotype and allele frequencies between patients and controls, increased risk for asthma was observed with the heterozygous genotype (GC), homozygous mutant genotype (CC) and mutant allele (C) of S2 SNP, with the heterozygous genotype (CT), homozygous mutant genotype (TT) and 
Table 3 Association of five polymorphisms in ADAM33 with asthma in Indian children

\begin{tabular}{|c|c|c|c|c|c|c|}
\hline \multirow[b]{2}{*}{ SNPS } & \multirow[b]{2}{*}{ Genotype } & \multicolumn{2}{|c|}{ Patients $(\mathrm{n}=211)$} & \multicolumn{2}{|c|}{ Control $(n=137)$} & \multirow[b]{2}{*}{ OR (95\% Cl) P-value } \\
\hline & & $(\mathrm{N})$ & (\%) & $(\mathrm{N})$ & $(\%)$ & \\
\hline \multirow{3}{*}{$F+1(G>A)$} & GA & 94 & 44.5 & 73 & 53.3 & $1.32(77-2.26) 0.310$ \\
\hline & AA & 78 & 37.0 & 24 & 17.5 & $3.33(1.76-6.29)<0.001$ \\
\hline & $G$ & 172 & 40.8 & 153 & 55.8 & 1 (reference) \\
\hline \multirow{4}{*}{ V4 $(C>G)$} & CG & 90 & 42.7 & 58 & 42.3 & $1.51(0.84-2.69) 0.168$ \\
\hline & $\mathrm{GG}$ & 87 & 41.2 & 46 & 33.6 & $1.84(1.01-3.34) 0.015^{* 1}$ \\
\hline & $\mathrm{C}$ & 158 & 37.4 & 124 & 45.3 & 1 (reference) \\
\hline & $G$ & 264 & 62.6 & 150 & 54.7 & $1.38(1.02-1.88) 0.031^{* 2}$ \\
\hline \multirow[t]{2}{*}{$\mathrm{ST}+4(\mathrm{~A}>\mathrm{C})$} & $\mathrm{AA}$ & 38 & 18.0 & 37 & 27.0 & 1 (reference) \\
\hline & $A C$ & 94 & 44.5 & 59 & 43.1 & $1.55(0.88-2.71) 0.123$ \\
\hline \multirow{4}{*}{$\mathrm{S} 2(\mathrm{G}>\mathrm{C})$} & GC & 85 & 40.3 & 51 & 37.2 & $6.66(3.58-12.42)<0.001$ \\
\hline & $\mathrm{CC}$ & 108 & 51.2 & 14 & 10.2 & $30.86(14.44-65.94)<0.001$ \\
\hline & G & 121 & 28.7 & 195 & 71.2 & 1 (reference) \\
\hline & C & 301 & 71.3 & 79 & 28.8 & $6.14(4.38-8.59)<0.001$ \\
\hline \multirow[t]{5}{*}{$\mathrm{ST}+5(\mathrm{C}>\mathrm{T})$} & $\mathrm{CC}$ & 26 & 12.3 & 33 & 24.1 & 1 (reference) \\
\hline & СT & 94 & 44.5 & 67 & 48.9 & $1.78(0.97-3.25) 0.020^{* 5}$ \\
\hline & TT & 91 & 43.1 & 37 & 27.0 & $3.12(1.65-5.92)<0.001$ \\
\hline & C & 146 & 34.6 & 133 & 48.5 & 1 (reference) \\
\hline & $\mathrm{T}$ & 276 & 65.4 & 141 & 51.5 & $1.783(1.307-2.432)<0.001$ \\
\hline
\end{tabular}

Abbreviations: $\mathrm{Cl}$, confidence interval; OR, odds ratio; SNP, single-nucleotide polymorphism.

After Bonferroni's correction $P$ corr $^{* 1}=0.046 ;$ corr $^{* 2}=0.040 ; P$ corr $^{* 3}=0.036 ; P$ corr $^{*}{ }^{*}=0.032$; and $P$ corr $^{*} 5=0.060$.

Table 4 Association of ADAM33 gene polymorphisms with severity of asthma

\begin{tabular}{|c|c|c|c|c|c|c|c|}
\hline \multirow[b]{2}{*}{ Genotype } & \multirow{2}{*}{$\begin{array}{c}\text { Control }(n=) \\
N(\%)\end{array}$} & \multicolumn{2}{|c|}{ Mild intermittent $(\mathrm{n}=51)$} & \multicolumn{2}{|r|}{ Mild persistent $(\mathrm{n}=127)$} & \multicolumn{2}{|c|}{ Moderate persistent (33) } \\
\hline & & $\mathrm{N}(\%)$ & OR $(95 \% \mathrm{Cl})$ & $\mathrm{N}(\%)$ & OR $(95 \% \mathrm{Cl})$ & N (\%) & OR $(95 \% \mathrm{Cl})$ \\
\hline GG & $40(29.2)$ & $11(21.6)$ & 1 (reference) & $22(17.3)$ & 1 (reference) & $7(21.2)$ & 1 (reference) \\
\hline GA & $73(53.3)$ & $21(41.2)$ & $1.04(0.45-2.38) 0.915$ & $53(41.7)$ & $1.32(.71-2.47) 0.387$ & $20(60.6)$ & $1.56(0.61-4.02) 0.352$ \\
\hline AA & $24(17.5)$ & $19(37.3)$ & $2.87(.17-7.07) 0.021$ & $52(40.9)$ & $3.94(1.94-8.01)<0.001$ & $6(18.2)$ & $1.43(0.43-4.75) 0.561$ \\
\hline $\mathrm{CC}$ & $33(24.1)$ & $11(21.6)$ & 1 (reference) & $19(15.0)$ & 1 (reference) & $4(12.1)$ & 1 (reference) \\
\hline CG & $58(42.3)$ & $19(37.3)$ & $0.98(.42-2.31) 0.968$ & $53(41.7)$ & $1.58(0.8-3.12) 0.181$ & $18(54.5)$ & $2.56(0.799-8.20) 0.11$ \\
\hline GG & $46(33.6)$ & $21(41.2)$ & $1.37(0.58-3.22) 0.471$ & $55(43.3)$ & $2.07(1.07-4.13) 0.037$ & $11(33.3)$ & $1.97(0.577-6.74) 0.27$ \\
\hline \multicolumn{8}{|l|}{$S T+4 A>C$} \\
\hline AA & $37(27.0)$ & $7(13.7)$ & 1 (reference) & $28(22.0)$ & 1 (reference) & 3. $(9.1)$ & 1 (reference) \\
\hline GG & $72(52.6)$ & $6(11.8)$ & 1 (reference) & $12(9.4)$ & 1 (reference) & 0 & 1 (reference) \\
\hline GC & $51(37.2)$ & $16(31.4)$ & 3.76 (1.37-10.28) 0.010 & $53(41.7)$ & $6.24(3.03-12.84)<0.001$ & $16(48.5)$ & $3.87(1.56-9.55) .003$ \\
\hline $\mathrm{CC}$ & $14(10.2)$ & $29(56.9)$ & $24.86(8.7-70.96)<0.0001$ & $62(48.8)$ & $26.57(11.44-61.70)<0.0001$ & $17(51.5)$ & NC \\
\hline \multicolumn{8}{|l|}{$S T+5 C>T$} \\
\hline $\mathrm{CC}$ & $33(24.1)$ & $9(17.6)$ & 1 (reference) & $14(11)$ & 1 (reference) & $3(9.1)$ & 1 (reference) \\
\hline СТ & 67 (48.9) & $20(39.2)$ & 1.09 (0.449-2.66) 0.842 & $58(45.7)$ & $2.04(0.99-4.18)(0.051)$ & $16(48.5)$ & $2.63(.73-9.65) 0.146$ \\
\hline TT & $37(27.0)$ & $22(43.1)$ & $2.180(0.881-5.39) 0.092$ & $55(53.3)$ & $3.50(1.65-7.43) 0.001$ & $14(42.4)$ & $4.16(1.09-15.7) 0.036$ \\
\hline
\end{tabular}

Abbreviations: $\mathrm{Cl}$, confidence interval; $\mathrm{NC}$, not calculated; OR, odds ratio. 
mutant allele of ST+5 SNP (T), the homozygous mutant genotype (CC) and mutant allele (C) of ST+4 SNP, the homozygous mutant genotype (GG) and mutant allele (G) of V4 SNP and with the homozygous mutant genotype (AA) and mutant allele (A) of $\mathrm{F}+1$ SNP. F+1, V4 and ST+4 heterozygous genotypes (GA, CG and AC, respectively) were not significantly distributed among cases and controls.

A case-only analysis was performed to observe the association between family history of asthma and total hospitalization rates. Among all five ADAM33 gene polymorphisms studied (F+1, V4, $\mathrm{ST}+4, \mathrm{~S} 2$ and $\mathrm{ST}+5)$, the homozygous mutant genotype of $\mathrm{ST}+5$ SNP, the heterozygous genotype of ST +4 , as well as V4, showed a high total hospitalization rate (Supplementary data file $1 ; P<0.05$ ). The homozygous mutant genotype of $\mathrm{ST}+5$ was observed to be significantly different among cases with a positive family history $(\mathrm{OR}=1.77$ 95\%, confidence interval: 0.98-3.19), $P=0.04$ ), whereas the heterozygous genotype (AC) of ST+4 SNP observed a marginally significant difference among cases with a positive family history (OR=1.72 95\% confidence interval: 0.95-3.11, $P=0.0531$; Supplementary data file 2).

\section{Association of ADAM33 gene polymorphisms with severity of asthma}

The genotype and allele frequencies of $A D A M 33$ gene polymorphisms in subgroups of asthma patients and in healthy controls are shown in Table 4. After comparing genotype and allele frequencies between asthma severity subgroups and controls, individuals with the homozygous mutant genotype (AA) of F+1 SNP, the homozygous mutant genotype (CC) of ST+4 SNP and the heterozygous and homozygous mutant genotypes (GC and CC) of S2 SNP were at increased risk for mild intermittent asthma. Polymorphisms V4 and ST+5 were not significantly associated with mild intermittent asthma. Individuals with the homozygous mutant genotype (AA) of F+1 SNP, the homozygous mutant genotype (GG) of V4 SNP, the heterozygous and homozygous mutant genotypes (GC and CC) of S2 SNP and the heterozygous and homozygous mutant genotypes (CT and TT) of ST+5 SNP were at increased risk for mild persistent asthma. Genotypes of ST+4 SNP were not statistically significantly associated with mild persistent asthma. Individuals with the heterozygous genotype (GC) of S2 SNP and the homozygous mutant genotypes of $\mathrm{ST}+5$ and $\mathrm{ST}+4 \mathrm{SNPs}$ (TT, CC) were at risk for moderate persistent asthma. SNPs F+1 and V4 were not significantly associated with moderate persistent asthma. Significant associations were observed with subgroups of asthma severity, but no single SNP was consistently associated with increasing severity of asthma across all subgroups.

\section{Haplotype analysis of ADAM33 polymorphisms}

For statistical advantage, haplotypes with a frequency of $<1 \%$ were excluded, as shown in Table 5. In asthma patients, the frequencies of haplotype combinations AGCCT, GGACT and AGCCC were higher in patients and may be responsible for the risk of developing disease asthma, whereas frequencies of haplotype combinations ACAGT, AGCGC, AGCGT, GCAGC and GCCGT were lower in patients, which shows protective association with asthma. For all cases and controls, LD-measured $D^{\prime}$ was high between most of the tested polymorphisms in the ADAM33 gene. (Supplementary data file 3) .A total of 10 pairs were observed, out of which 7 pairs, namely, $\mathrm{F}+1 / \mathrm{ST}+4, \mathrm{~F}+1 / \mathrm{ST}+5, \mathrm{~V} 4 / \mathrm{S} 2, \mathrm{~V} 4 / \mathrm{ST}+5, \mathrm{ST}+4 / \mathrm{S} 2, \mathrm{ST}+4 / \mathrm{ST}+5$ and $\mathrm{S} 2 / \mathrm{ST}+5$, were in strong $\mathrm{LD}$; in controls, 6 pairs, namely, $\mathrm{F}+1 / \mathrm{V} 4$, $\mathrm{F}+1 / \mathrm{ST}+5, \mathrm{~V} 4 / \mathrm{ST}+4, \mathrm{~V} 4 / \mathrm{S} 2, \mathrm{~V} 4 / \mathrm{ST}+5$ and $\mathrm{S} 2 / \mathrm{ST}+5$, were in strong LD (Yates's corrected $P$ value $<0.05$ and $\left|D^{\prime}\right| \neq 0$ ).
Table 5 Distribution of ADAM33 gene SNPs haplotypes and association with risk of Asthma

\begin{tabular}{|c|c|c|c|c|c|}
\hline Total no. & Haplotype & $\begin{array}{c}\text { Case } \\
(\mathrm{n}=422)^{\mathrm{a}}\end{array}$ & $\begin{array}{c}\text { Control } \\
(\mathrm{n}=274)^{\mathrm{a}}\end{array}$ & P-value & OR \\
\hline 1 & AGCCT & 16.2 & 2.9 & $<0.001$ & $6.50(2.9-14.87)$ \\
\hline 2 & GGACT & 8.4 & 1.4 & $<0.001$ & $6.10(2.04-20.47)$ \\
\hline 3 & ACCCT & 7.9 & - & $\mathrm{NC}$ & $\mathrm{NC}$ \\
\hline 4 & AGCCC & 6.6 & 0.9 & $<0.001$ & $9.66(2.22-59.17)$ \\
\hline 5 & GGCCT & 5.5 & 5.9 & 0.827 & $0.93(0.46-1.88)$ \\
\hline 6 & AGACT & 5.3 & 3.9 & 0.391 & $1.38(0.63-3.07)$ \\
\hline 7 & GCAGC & 5.3 & 9.3 & 0.019 & $0.50(0.27-0.94)$ \\
\hline 8 & AGAGT & 3.8 & 5.8 & 0.208 & $0.64(0.30-1.36)$ \\
\hline 9 & GGAGC & 3.3 & 3.4 & 0.981 & $1.01(0.40-2.57)$ \\
\hline 10 & ACCGT & 3.1 & - & $\mathrm{NC}$ & NC \\
\hline 11 & ACACT & 3.1 & - & $\mathrm{NC}$ & NC \\
\hline 12 & GGCCC & 3.1 & 1.9 & 0.308 & $1.71(0.56-5.56)$ \\
\hline 13 & GCCCT & 2.8 & - & $\mathrm{NC}$ & $\mathrm{NC}$ \\
\hline 14 & ACCCC & 2.8 & 1.3 & 0.501 & $1.98(0.58-7.33)$ \\
\hline 15 & GGACC & 2.6 & 1.7 & 0.501 & $1.44(0.46-4.81)$ \\
\hline 16 & GCCCC & 2.5 & 3.7 & 0.432 & $0.71(0.27-1.82)$ \\
\hline 17 & AGCGT & 2.4 & 7.7 & 0.001 & $0.29(0.13-0.66)$ \\
\hline 18 & GGCGT & 2.2 & 3.7 & 0.230 & $0.58(0.21-1.55)$ \\
\hline 19 & ACCGC & 2.2 & 3.5 & 0.230 & $0.51(0.21-1.55)$ \\
\hline 20 & GCACC & 1.9 & 1.1 & 0.408 & $1.75(0.42-8.37)$ \\
\hline 21 & AGAGC & 1.5 & 1.7 & 0.677 & $0.78(0.21-2.96)$ \\
\hline 22 & ACAGT & 1.5 & 6.7 & $<0.001$ & $0.21(0.07-0.56)$ \\
\hline 23 & AGCGC & 1.3 & 4.7 & 0.001 & $0.20(0.06-0.61)$ \\
\hline 24 & ACACC & 1.3 & 0.8 & 0.557 & $1.63(0.28-12.21)$ \\
\hline 25 & GCACT & 1.2 & 3.1 & 0.099 & $0.40(0.11-1.36)$ \\
\hline 26 & GCCGT & 1.1 & 4.8 & 0.001 & $0.20(0.06-0.61)$ \\
\hline
\end{tabular}

Abbreviations: $\mathrm{Cl}$, confidence interval; $\mathrm{NC}$, not calculated; OR, odds ratio; SNP, singlenucleotide polymorphism.

${ }^{\text {a } T o t a l}$ number of chromosomes.

\section{Interaction of genotype with environmental risk factors}

A case and control study was separately conducted to reveal any possible gene-environment interactions. Environmental risk factors included (1) type of road categorized into three subgroups-road of occasional traffic, busy road with vehicular traffic and residential area near highway; and (2) presence of industrial factor near residential area. Although all factors were prominent in patients as compared with controls, none of the genotype-environment risk factor interactions significantly modulated risk for asthma. Only ST+4 genotypes were significantly distributed among type-of-road subgroups. Near-highway-predicted percentages for the homozygous normal genotype (AA), the heterozygous genotype (AC) and the homozygous mutant genotype (CC) of ST+4 SNP were 11.8, 29.4 and 58.8\%, respectively. Busy road with vehicular traffic-predicted percentages for homozygous normal genotype (AA), heterozygous genotype (AC) and homozygous mutant genotype (CC) of ST+4 SNP were 0.0, 40.0 and $60.0 \%$, respectively. Road of occasional traffic-predicted percentages for homozygous normal genotype (AA), heterozygous genotype (AC) and the homozygous mutant genotype (CC) of ST+4 SNP were 22.0, 47.0 and $31.1 \%$, respectively. For all three types of road subgroups compared with ST+4 genotypes, Fisher's exact $P$-value was 0.002 , which indicates that an area of heavy traffic is a risk factor that initiates gene-environment interaction with asthma. (Insignificant data not shown regarding gene-environment interactions.) 
Table 6 Association of five genotyped ADAM33 gene polymorphisms in different populations

\begin{tabular}{|c|c|c|c|c|c|c|c|}
\hline \multirow[b]{2}{*}{ Reference } & \multirow{2}{*}{$\begin{array}{l}\text { Study population } \\
\text { cc, fa and coh }\end{array}$} & \multirow{2}{*}{$\begin{array}{l}\text { N2 } \\
\text { Case/controls; families (Individuals) }\end{array}$} & \multicolumn{5}{|c|}{ ADAM33 SNPs and reported associations } \\
\hline & & & $F+1$ & S2 & $S T+4$ & $S T+5$ & V4 \\
\hline \multirow[t]{4}{*}{ Van Eerdewegh et al. ${ }^{7}$} & US/UK combined (cc) & $130 / 217$ & NR & NR & $A$ & NR & $A$ \\
\hline & UK (cc) & Not reported & $A$ & $A$ & $A$ & NR & A \\
\hline & US (cc) & Not reported & NR & NR & NR & NR & NR \\
\hline & US/UK (fa) & $460(1840)$ & NR & NR & NR & NR & NA \\
\hline \multirow[t]{3}{*}{ Lind et al. ${ }^{19}$} & Mexican (cc) & $190 / 160$ & NR & NR & NR & NR & NA \\
\hline & Puerto Rican (cc) & $183 / 165$ & NR & NR & NR & NR & NA \\
\hline & Mexican/Puerto Rican (fa) & $583(1749)^{3}$ & NR & NR & NR & NR & NA \\
\hline \multirow[t]{3}{*}{ Raby et al. ${ }^{20}$} & Non-Hispanic white (fa) & $474(1462)$ & NR & NA & NA & NA & NA \\
\hline & Hispanic (fa) & 47 (149) & NR & NA & NA & NA & NA \\
\hline & African-American (fa) & $66(203)$ & NR & NA & NA & NA & NA \\
\hline \multirow[t]{2}{*}{ Werner et al. ${ }^{15}$} & German (cc) & $48 / 499$ & NA & NA & NA & NA & NA \\
\hline & German (fa) & $171(732)$ & A & $A^{3}$ & A & A & NA \\
\hline \multirow[t]{4}{*}{ Howard et al. ${ }^{16}$} & African-American (cc) & $161 / 265$ & NR & $A$ & NA & NR & NA \\
\hline & US White (cc) & $220 / 229$ & NR & $A^{3}$ & NA & NR & NA \\
\hline & US Hispanic (cc) & $113 / 127$ & NR & $A$ & NA & NR & NA \\
\hline & Dutch White (cc) & $180 / 133$ & NR & NA & NA & NR & $A$ \\
\hline \multirow[t]{2}{*}{ Blakey et al. ${ }^{25}$} & Icelandic (cc) & $348 / 262$ & $N A^{d}$ & NA & NA & NA & NA \\
\hline & Nottingham (fa) & $60(240)$ & $N A^{d}$ & NA & NA & NA & NA \\
\hline Hirota et al. ${ }^{17}$ & Japanese (cc) & $504 / 651$ & NA & $A$ & NA & NR & NA \\
\hline \multirow[t]{2}{*}{ Sakagami et al. ${ }^{18}$} & Japanese (cc) AIA & $102 / 120$ & NR & NR & NA & NR & NA \\
\hline & ATA (cc) & $282 / 120$ & NR & NR & NA & NR & NA \\
\hline Noguch et al. ${ }^{29}$ & Japanese (fa) & $155(538)$ & NA & NA & $A$ & NR & NA \\
\hline Thongngarm et al. ${ }^{28}$ & Thai (cc) & $200 / 100$ & NR & A & A & NR & NA \\
\hline \multirow[t]{2}{*}{ Vergara et al. ${ }^{23}$} & Cartagena, Colombia (fa) & $429 / 401$ & NR & NA & NR & NR & NA \\
\hline & Cartagena, Colombia (fa) & $116(348)$ & NR & NA & NR & NR & NA \\
\hline Wang et al. ${ }^{25}$ & Chinese (cc) & $296 / 270$ & NA & NR & NR & NR & NR \\
\hline Su et al. ${ }^{14}$ & Chinese Han (cc) & $181 / 151$ & NR & NR & NR & NR & $A$ \\
\hline \multirow[t]{2}{*}{ Schedel et al. ${ }^{24}$} & German (cc) & $624 / 1248$ & NA & NA & NA & NA & NA \\
\hline & Cohort (coh) & $86 / 464$ & NA & NA & NA & NA & NA \\
\hline Kedda et al. ${ }^{27}$ & Australian (cc) & $612 / 473$ & NA & NR & NA & NR & NA \\
\hline Lee et $a l^{21}$ & Korean & $326 / 121$ & NR & NR & NR & NR & NA \\
\hline This study 2010 & India (cc) & $211 / 137$ & $A$ & $A$ & A & $A$ & $A$ \\
\hline
\end{tabular}

Abbreviations: AIA, aspirin-intolerant asthma; ATA, aspirin-tolerant asthma; cc, case control; coh, cohort study; fa, family study; NA, no association; NR, not done; SNP, single-nucleotide polymorphism.

$\mathrm{A}=$ showed positive association of SNPs with asthma

$\mathrm{NA}=$ done but no association found with asthma $(P<0.05)$.

$3=$ only a trend $(0.05<P \leqslant 0.065)$.

$N A^{d}=$ not associated with asthma on particular population but significant association found after combined meta-analysis on published literature.

\section{DISCUSSION}

The present case-control study was conducted to assess the association of specific ADAM33 gene polymorphisms ( $\mathrm{F}+1(\mathrm{rs} 5118980)$, V4(rs2787094), ST+4(rs44707), S2(rs528557) and ST+5(rs597980)) with childhood or childhood-onset asthma in children aged 1-15 years and in age- and sex-matched healthy controls. During the analysis of cases and controls, we found that S2 and ST+5 SNPs were significantly associated with asthma, whereas $\mathrm{F}+1, \mathrm{ST}+4$ and V4 homozygous mutant genotypes and mutant alleles were significantly different compared with controls.

Several groups have examined the association of ADAM33 gene polymorphisms $(\mathrm{F}+1, \mathrm{~V} 4, \mathrm{ST}+4, \mathrm{~S} 2$ and $\mathrm{ST}+5)$ with asthma in various populations and the findings are summarized in Table 6. Similar to our results, S2 gene polymorphism was reported to be associated with asthma in a UK-only population, ${ }^{7}$ in a family-based study on Germans, ${ }^{19}$ as well as in African-American, US White and US Hispanic, ${ }^{20}$ Japanese $^{21}$ and Thai $^{32}$ populations. The $S T+5$ gene polymorphism was associated with a family-based study conducted by Werner et al. ${ }^{19}$

The $S T+4$ ADAM33 gene polymorphism was found to be associated with US/UK combined and UK-only populations, ${ }^{7}$ in a German family-based study conducted by Werner et al., ${ }^{19}$ as well as in Thai case-control ${ }^{32}$ and Japanese family-based studies. ${ }^{33}$ We also found a significant association of the ST +4 homozygous mutant genotype and mutant allele with asthma.

In our study, we found a significant association of the homozygous mutant genotype and mutant allele of F+1 SNP with asthma. Similar to our result, the $F+1$ gene polymorphism has shown positive association in a UK-only population and in German family-based studies. ${ }^{7,19}$ Recently, Blakey et al. ${ }^{29}$ conducted transmission disequilibrium and case-control studies, followed by a meta-analysis of all existing data. The meta-analysis showed that $\mathrm{F}+1$ and $\mathrm{ST}+7$ (not performed in this study), which were not associated with asthma in most of the studies, were significantly associated with asthma. 
The V4 gene polymorphisms of the ADAM33 gene have shown association in US/UK combined, UK-only, Dutch White and Chinese Han populations. ${ }^{7,14,20}$ We also found significant association of the $\mathrm{ST}+4$ homozygous mutant genotype and mutant allele with asthma in our Indian population.

However, in contrast to our study, very large studies conducted by Lind ${ }^{23}$ and Raby et al..$^{24}$ investigating childhood asthma could not find any association between single ADAM33 SNPs or haplotypes and childhood asthma. No association was found between asthma and ADAM33 in Korean, Australian, Chinese, German, Japanese and Caribbean Coast of Colombian populations. ${ }^{21,25,27-29,31}$ A recent report by Bijanzadeh and colleagues also failed to find an association between asthma and the T1 SNP of the ADAM33 gene in a South Indian population. ${ }^{34}$ This may be because of allelic heterogeneity, a single disorder caused by different mutations within a gene. Another explanation is the difference in LD patterns between populations, which means that unobserved causal variants are the same in different populations, but that SNPs in strong $\mathrm{LD}$ with variants differ between populations or that the disease-causing variants are in strong LD with an SNP in one ethnic population, but not in others. Differences in the frequency of SNPs in cases and controls in different studies were summarized by Postma et al..$^{30}$

Comparison of our results with those of various studies referred to in Table 6 indicates that no single SNP was universally associated with the asthma phenotype. One explanation for these differences might be the heterogeneity of asthma. There may be genetic differences among subtypes of asthma, such as pediatric, allergic/non-allergic asthma and so on. Asthma was not defined by common criteria in these investigations.

Haplotypes are considered to carry information about possibly unobserved causal variants in the region ${ }^{33}$ in asthma patients; the frequencies of haplotype combinations AGCCT, GGACT and AGCCC were higher in patients, suggesting that these three haplotypes increase the risk of asthma. Furthermore, we found that frequencies of haplotypes ACAGT, AGCGC, AGCGT, GGAGC and GCCGT were lower in patients compared with healthy controls. This result may imply a protective role of these five haplotypes in combination with asthma in Indian children. Although ADAM33 might have a key role in asthma through airway wall remodeling, its exact role in disease susceptibility is unclear. In previous studies, polymorphisms in mRNA were shown to contribute to transcript stability. ${ }^{35,36}$ Therefore, it is likely that the susceptible allele present on the coding region of the ADAM33 transcript might affect its stability, which in turn might modulate the inflammation process. Our data strongly support the importance of ADAM33 in asthma across ethnic boundaries, and further investigations of the connections between genotypes and the functional roles of ADAM33 would be helpful to clarify the etiology of asthma. Given the recent advances in SNP genotyping, it is certain that more SNPs of this gene will be identified.

Our data suggest evidence for an association of the ADAM33 polymorphism with asthma risk. In conclusion, our study observed the significant association of SNPs $\mathrm{S} 2 \mathrm{G} / \mathrm{C}$ and $\mathrm{ST}+5 \mathrm{C} / \mathrm{T}$ of the $A D A M 33$ gene heterozygous and mutant genotypes and allele frequencies with asthma risk and significant association of F+1 G/A, ST+4 $\mathrm{A} / \mathrm{C}, \mathrm{V} 4 \mathrm{C} / \mathrm{G}$ mutant genotypes and alleles with increased asthma risk. Frequencies of haplotype combinations AGCCT, GGACT and AGCCC were higher in patients and may cause risk of developing asthma, whereas frequencies of haplotype combinations ACAGT, AGCGC, AGCGT, GCAGC and GCCGT were lower in patients, which shows protective association with asthma. Additional studies with a larger sample size and with long-term follow-ups will undoubtedly lead to a more thorough understanding of the role of the ADAM33 gene polymorphism in childhood asthma in the Indian population.

\section{ACKNOWLEDGEMENTS}

We acknowledge the financial support from the Department of Biotechnology, Government of India (letter no: BT/PR7115/Med/14/955/2006) for carrying out this work. We thank Dr Vikas Mishra for assistance in project designing. We thank all patients and healthy controls for providing blood samples. We thank Ms Rashmi Parihar at the Indian Institute of Technology, Kanpur, for her help with the RFLP analysis.

1 Palmer, L. J. \& Cookson, W.O.C.M. Genomic approaches to understanding asthma. Genome Res. 10, 1280-1287 (2002).

2 Aggarwal, A. N., Chaudhry, K., Chhabra, S. K., D'Souza, G. A., Gupta, D., Jindal, S. K. et al. Prevalence and risk factors for bronchial asthma in Indian adults: a multicentre study. Indian J. Chest Dis. Allied Sci. 48, 13-22 (2006).

3 Paramesh, H. Epidemiology of asthma in India. Indian J. Pediatr. 69, 309-312 (2002).

4 ISAAC Steering Committee. Worldwide variations in the prevalence of asthma symptoms: the International Study of Asthma and Allergies in Childhood (ISAAC). Eur. Respir. J 12, 315-335 (1998).

5 Hoffjan, S. \& Ober, C. Present status on the genetic studies of asthma. Curr. Opin. Immunol. 14, 709-717 (2002).

6 Global strategy for asthma management and prevention. Global Initiative for Asthma (Gina), National Heart, Lung and Blood Institute, US Department of Health and Human Services: National Institute of Health (NIH) Publication No 02-3659 (2005).

7 Van Eerdewegh, P., Little, R. D., Dupuis, J., Del Mastro, R. G., Falls, K., Simon, J. et al. Association of the ADAM33 gene with asthma and bronchial hyperresponsiveness. Nature 418, 426-430 (2002).

8 White, J. M. ADAMs: modulators of cell-cell and cell-matrix interactions. Curr. Opin. Cell Biol. 15, 598-606 (2003).

9 Martin, J., Eynstone, L. V., Davies, M., Williams, J. D. \& Steadman, R. The role of ADAM 15 in glomerular mesangial cell migration. J. Biol. Chem. 277, 33683-33689 (2002).

10 McFarlane, S. Metalloproteases: carving out a role in axon guidance. Neuron 37, 559-562 (2003).

11 Hundhausen, C., Misztela, D., Berkhout, T. A., Broadway, N., Saftig, P., Reiss, K. et al. The disintegrin-like metalloproteinase ADAM10 is involved in constitutive cleavage of CX3CL1 (fractalkine) and regulates CX3CL1-mediated cell-cell adhesion. Blood 102, 1186-1195 (2003).

12 Seals, D. F. \& Courtneidge, S. A. The ADAMs family of metalloproteases: multidomain proteins with multiple functions. Genes Dev. 17, 7-30 (2003).

13 Yoshinaka, T., Nishii, K., Yamada, K., Sawada, H., Nishiwaki, E., Smith, K. et al. Identification and characterization of novel mouse and human ADAM33s with potential metalloprotease activity. Gene 282, 227-236 (2002).

14 Su, D., Zhang, X., Sui, H., Lu, F., Jin, L. \& Zhang, J. Association of ADAM33 gene polymorphisms with adult allergic asthma and rhinitis in a Chinese Han population. BMC Med. Genet. 9, 82-87 (2008).

15 Schneider, S., Roessli, D. \& Excoffier, L. Arlequin (version 2.00): software for population genetics data analysis, Genetics and Biometry Laboratory, University of Geneva, Switzerland (2000).

16 Upadhyay, R., Jain, M., Kumar, S., Ghoshal, U. C. \& Mittal, B. Functional polymorphisms of cyclooxygenase-2 (COX-2) gene and risk for esophageal squmaous cell carcinoma. Mutat. Res. 663, 52-59 (2009).

17 Jongepier, H., Boezen, H. M., Dijkstra, A., Howard, T. D., Vonkz, J. M., Koppelmanz, G. H. et al. Polymorphisms of the ADAM33 gene are associated with accelerated lung function decline in asthma. Clin. Exp. Allergy 34, 757-760 (2004).

18 Simpson, A., Maniatis, N., Jury, F., Cakebread, J. A., Lowe, L. A., Holgate, S. T. et al. Polymorphisms in a disintegrin and metalloprotease 33 (ADAM33) predict impaired early-life lung function. Am. J. Respir. Crit. Care Med. 172, 55-60 (2005).

19 Werner, M., Herbon, N., Gohlke, H., Altmüller, J., Knapp, M., Heinrich, J. et al. Asthma is associated with single-nucleotide polymorphisms in ADAM33. Clin. Exp. Allergy 34, 26-31 (2004).

20 Howard, T. D., Postma, D. S., Jongepier, H., Moore, W. C., Koppelman, G. H., Zheng, S. $\mathrm{L}$. et al. Association of a disintegrin and metalloprotease 33 (ADAM33) gene with asthma in ethnically diverse populations. J. Allergy Clin. Immunol. 112, 717-722 (2003).

21 Hirota, T., Hasegawa, K., Obara, K., Matsuda, A., Akahoshi, M., Nakashima, K. et al. Association between ADAM33 polymorphisms and adult asthma in the Japanese Population. Clin. Exp. Allergy 36, 884-891 (2006).

22 Sakagami, T., Jinnai, N., Nakajima, T., Sekigawa, T., Hasegawa, T., Suzuki, E. et al. ADAM33 polymorphisms are associated with aspirin-intolerant asthma in the Japanese population. J. Hum. Genet. 52, 66-72 (2007).

23 Lind, D. L., Choudhry, S., Ung, N., Ziv, E., Avila, P. C., Salari, K. et al. ADAM33 is not associated with asthma in Puerto Rican or Mexican populations. Am. J. Respir. Crit. Care Med. 168, 1312-1316 (2003).

24 Raby, B. A., Silverman, E. K., Kwiatkowski, D. J., Lange, C., Lazarus, R. \& Weiss, S. T. ADAM33 polymorphisms and phenotype associations in childhood asthma. J. Allergy Clin .Immunol. 113, 1071-1078 (2004). 
25 Lee, J. H., Park, H. S., Park, S. W., Jang, A. S., Uh, S. T., Rhim, T. et al. ADAM33 polymorphism: association with bronchial hyper-responsiveness in Korean asthmatics. Clin. Exp. Allergy 34, 860-865 (2004).

26 Wang, P., Liu, Q. J., Li, J. S., Li, H. C., Wei, C. H., Guo, C. H. et al. Lack of association between $A D A M 33$ gene and asthma in a Chinese population. Int. J. Immunogenet. 33, 303-306 (2006).

27 Vergara, C. I., Acevedo, N., Jiménez, S., Martínez, B., Mercado, D., Gusmão, L. et al. A six-SNP haplotype of ADAM33 is associated with asthma in a population of Cartagena, Colombia. Int. Arch. Allergy Immunol. 152, 32-40 (2010).

28 Schedel, M., Depner, M., Schoen, C., Weiland, S. K., Vogelberg, C., Niggemann, B. et al. The role of polymorphisms in ADAM33, a disintegrin and metalloprotease 33, in childhood asthma and lung function in two German populations. Respir. Res. 7, 91 (2006).

29 Blakey, J., Halapi, E., Bjornsdottir, U. S., Wheatley, A., Kristinsson, S., Upmanyu, R. et al. Contribution of ADAM33 polymorphisms to the population risk of asthma. Thorax 60, 274-276 (2005).

30 Postma, D. S. \& Howard, T. ADAM33 gene: confirming a gene without linkage. Clin. Exp. Allergy 34, 1-3 (2004).
31 Kedda, M. A., Duffy, D. L., Bradley, B., O'Hehir, R. E. \& Thompson, P. J. ADAM33 haplotypes are associated with asthma in a large Australian population. Eur. J. Hum. Genet. 14, 1027-1036 (2006).

32 Thongngarm, T., Jameekornrak, A., Limwongse, C., Sangasapaviliya, A., Jirapongsananuruk, O., Assawamakin, A. et al. Association between ADAM33 polymorphisms and asthma in a Thai population. Asian Pac. J. Allergy Immunol. 26, 205-211 (2008).

33 Noguchi, E., Ohtsuki, Y., Tokunaga, K., Yamaoka-Sageshima, M., Ichikawa, K., Aoki, T. et al. ADAM33 polymorphisms are associated with asthma susceptibility in a Japanese population. Clin. Exp. Allergy 36, 602-608 (2006).

34 Bijanzadeh, M., Ramachandra, N. B., Mahesh, P. A., Mysore, R. S., Kumar, P., Manjunath, B. S. et al. Association of IL-4 and ADAM33 gene polymorphisms with asthma in an Indian population. Lung 5, 415-422 (2010).

35 Yang, J., Fan, G. H., Wadzinski, B. E., Sakurai, H. \& Richmond, A. Protein phosphatase $2 \mathrm{~A}$ interacts with and directly dephosphorylates RelA. J. Biol. Chem. 276, 47828-47833 (2001).

36 Suzuki, A., Yamada, R., Chang, X., Tokuhiro, S., Sawada, T., Suzuki, M. et al. Functional haplotypes of PADI4, encoding citrullinating enzyme peptidylarginine deiminase 4 , are associated with rheumatoid arthritis. Nat. Genet. 34, 395-402 (2003).

Supplementary Information accompanies the paper on the Journal of Human Genetics website (http://www.nature.com/jhg) 